\title{
QUANTIDADE DE RESIDUOS SÓLIDOS COLETADOS PELO PROGRAMA TANGARÁ RECICLA: UMA ANÁLISE COMPARATIVA DOS PRIMEIROS SEMESTRES 2010/2011
}

\author{
Jair de Oliveira ${ }^{1}$ \\ Cleci Grzebieluckas ${ }^{2}$
}

\begin{abstract}
RESUMO
O estudo teve como objetivo quantificar os materiais reciclados pela Cooperativa de Produção de Resíduos Sólidos de Tangará da Serra e analisar se houve evolução na quantidade e valores entre o primeiro semestre de 2010 e primeiro semestre de 2011. É uma pesquisa de natureza exploratória e descritiva com abordagem quali-quantititiva. Os instrumentos de coleta utilizados foram roteiro estruturado e entrevistas abertas. Os resultados indicaram que houve uma redução de $7,41 \%$ na quantidade e de $22,75 \%$ nos valores das vendas entre o primeiro semestre de 2010 e o 2011. Esta redução se deu em virtude de que a cooperativa não conseguiu fazer aproveitamento do excedente devido o limitado número de cooperados que não conseguem classificar o montante de resíduos coletados no município. As maiores dificuldades destacadas pelos membros da diretoria da Cooperativa e por alguns associados foi que existe a necessidade de uma melhor infraestrutura do local, maior apoio nas questões gerenciais e burocráticas demandando uma assessoria que auxilie nos trâmites administrativos, comerciais e gerenciais.
\end{abstract}

Palavras Chave; Resíduos sólidos. Coleta seletiva. Reciclagem. Lixo

\section{INTRODUÇÃO}

Com a escassez de recursos naturais, aliada aos problemas relacionados à disposição inadequada dos resíduos no meio ambiente, surge a necessidade de se realizar a reciclagem, sistema de recuperação de recursos projetado para recuperar e reutilizar resíduos, transformando-os em substâncias e materiais úteis à sociedade, denominados de matéria secundária (RIBEIRO; LIMA, 2000). A coleta seletiva do lixo contribui para a melhoria do meio ambiente, na medida em que reduz o consumo de energia, diminui a poluição do solo, da água e do ar e prolonga a vida útil dos aterros sanitários.

O aumento dos resíduos sólidos se deve à produção indiscriminada de embalagens recicláveis, aos hábitos alimentares cada vez mais estimulados pela propaganda dos produtos convenientes (fast-food e congelados), pelas novas tecnologias entre outros. Os principais componentes desses resíduos são jornais e revistas, isopor, garrafas, embalagens diversas, papelão, latas de alumínio e demais componentes que podem ser reciclados e transformados em novos produtos (COELHO, 2001). Em 2010, o Brasil produziu 195 mil toneladas de

\footnotetext{
${ }^{1}$ Acadêmico do Curso de Ciências Contábeis da UNEMAT - Campus de Tangará da Serra, e-mail: (jairoliveira90@hotmail.com).

${ }_{2}^{2}$ Doutora em Engenharia de Produção Professora do curso de Ciências Contábeis da UNEMAT - Campus de Tangará da Serra, e-mail: (cleci@unemat.br).
} 
Quantidade de residuos sólidos coletados pelo programa Tangará Recicla: uma análise comparativa dos primeiros semestres 2010/2011

Jair de Oliveira

Cleci Grzebieluckas

resíduos sólidos por dia representando um aumento de $7 \%$ em relação ao ano de 2009 que foram geradas 182 toneladas (AGENCIA ESTADO, 2011).

Segundo dados do Instituto Brasileiro de Geografia e Estatística (IBGE, 2010) dos 5.564 municípios brasileiros, 653 possuem manejo de resíduos sólidos com participação de catadores nas ações de coleta seletiva, 445 com participação organizada através de cooperativas ou associações, 279 com participação isolada e 41 com outra forma de participação em coleta seletiva de lixo.

O Município de Tangará da Serra possui população total de 81.918 habitantes $(92,6 \%$ na área urbana). A Prefeitura realiza, alternadamente, a coleta de resíduos sólidos urbanos, segregados em secos e úmidos (sendo denominado pelo município como lixo orgânico e lixo reciclável). O lixo orgânico é coletado em caminhões específicos de coletas com sistema mecânico de compactação que leva esses resíduos para o aterro sanitário. Já a coleta dos materiais reciclados é realizada por caminhões que levam esses materiais para um galpão da Cooperativa de Produção de Resíduos Sólidos de Tangará da Serra (COOPERTAN) onde passam pela triagem, classificação e depois são prensados e comercializados na região.

Neste contexto o estudo teve como objetivo quantificar os materiais reciclados pela COOPERTAN e analisar se houve evolução na quantidade e valores entre o primeiro semestre de 2010 e primeiro semestre de 2011. Justifica-se em razão de que existem diversas cooperativas de produtos reciclados, contudo, pouco se sabe sobre quais os tipos de materiais são reciclados em maior quantidade, bem como os preços praticados, principalmente na COOPERTAN de Tangará da Serra MT.

\section{REFERENCIAL TEÓRICO}

\subsection{Coleta seletiva e panorama do lixo e catadores no Brasil}

A coleta seletiva é a separação prévia de materiais passíveis de reaproveitamento de resíduos que normalmente são chamados de lixo (PIERONI, 1994). Estes materiais são separados no lugar em que foram gerados, mediante um acondicionamento distinto para cada componente (WALDMAN; SCHNEIDER, 2000). Do ponto de vista das normas e legislações, os resíduos sólidos urbanos são representados por materiais como: papel, vidro, plástico, metal, matéria orgânica, etc... Já do ponto de vista econômico, o lixo constitui um material desperdiçado pela população, e assim sendo, estes materiais estão relacionados com as sobras 
Quantidade de residuos sólidos coletados pelo programa Tangará Recicla: uma análise comparativa dos primeiros semestres 2010/2011

Jair de Oliveira

Cleci Grzebieluckas

domésticas enquanto resíduo está relacionados com sobras de processos produtivos e demandas que orientam a construção de uma racionalidade ambiental (LEFF, 2001)

No Brasil existem 1919 cidades (34,48\%) que tem uma frequência diária de coleta de resíduos sólidos nos Bairros da cidade, 1440 cidades (25,88\%) com uma frequência de coleta de resíduos sólidos nos Bairros de três vezes na semana, 720 cidades (12,94\%) com uma frequência de coleta de resíduos sólidos nos Bairros duas vezes na semana, 576 cidades $(10,35 \%)$ com uma frequência de uma vez na semana, 325 cidades $(5,84 \%)$ com frequência de diária superior a três vezes por semana.

No Estado de Mato Grosso existem 27 cidades (19,14\%) que tem uma frequência diária de coleta de resíduos sólidos nos Bairros da cidade, 31 cidades (21,98\%) com uma frequência de três vezes na semana, 26 cidades $(18,43 \%)$ com uma frequência de duas vezes na semana, 24 cidades $(17,02 \%)$ com uma frequência de coleta de resíduos sólidos nos Bairros da cidade de uma vez na semana, e 16 cidades $(11,34 \%)$ com outras frequências de coleta de resíduos sólidos nos Bairros da cidade (IBGE 2008).

No entanto no Brasil, do total de resíduos sólidos urbanos coletados, apenas $30 \%$ recebem algum tipo de tratamento, enquanto os $70 \%$ restantes são lançados em lixões, causando sérios impactos ambientais. Dentre os impactos causados pelo lançamento inadequado de resíduos sólidos urbanos, destacam-se as várias doenças, tais como a salmonelose, a hepatite, a febre tifoide e paratifoide, a leptospirose, dentre outras, contraídas pelo contato direto com os resíduos ou por contato indireto ou com a água contaminada (LEITE, 2003).

Figueiredo (2005) afirma que os órgãos governamentais recomendam que os resíduos sólidos domiciliares devam ser lançados em aterros sanitários controlados por processo de tratamento do chorume e também que sejam feitas drenagens. Os resíduos sólidos constituem problemas sanitários relevantes quando não são acondicionados, coletados, transportados, tratados, e dispostos adequadamente. A procura de alternativas para proteger e minimizar as agressões ao meio ambiente e reduzir os risco à saúde humana tem se tornado constante, devido ao desenvolvimento e crescimento econômico desenfreado, à explosão demográfica contínua, à omissão por parte dos poderes públicos e à ausência de informação da população tornando difícil a obtenção de sucesso na resolução destas questões por falta de planejamento, gerenciamento e políticas públicas efetivas. (LIMA, 2001). 


\subsection{Sociedades Cooperativas de catadores de produtos recicláveis.}

Sociedades cooperativas estão reguladas pela Lei $n^{\circ}$ 5.764, de 1971 que define a Política Nacional de Cooperativismo e instituiu o regime jurídico das cooperativas. São sociedades de pessoas de natureza civil, com forma jurídica própria, constituídas para prestar serviços aos associados e que se distinguem das demais sociedades pelas seguintes características:

a) adesão voluntária, com número ilimitado de associados, salvo impossibilidade técnica de prestação de serviços;

b) variabilidade do capital social, representado por cotas-partes;

c) limitação do número de cotas-partes para cada associado, facultado, porém, o estabelecimento de critérios de proporcionalidade;

d) inacessibilidade das quotas partes do capital a terceiros, estranhos à sociedade;

e) retorno das sobras liquidas do exercício, proporcionalmente às operações realizadas pelo associado, salvo deliberação em contrário da assembléia geral;

f) quorum para o funcionamento e deliberação da assembléia geral baseado no número de associados e não no capital;

g) indivisibilidade do fundos de reserva e de assistência técnica educacional e social;

h) neutralidade política e indiscriminação religiosa, racial e social;

i) prestação de assistência aos associados, e, quando previsto nos estatutos, ao empregados da cooperativa;

j) área de admissão de associados limitada às possibilidades de reunião, controle, operações e prestação de serviços (Lei no 5.764, de 1971).

O quadro social das cooperativas é composto de pessoas físicas e jurídicas definido por uma assembleia geral com normas prevista em estatuto social. O mandato dos membros do conselho fiscal das cooperativas é de até 3 (três) anos, observada a renovação de, ao menos, 2 (dois) membros a cada eleição, sendo 1 (um) efetivo e 1 (um) suplente. É vedado distribuir qualquer espécie de benefício às quotas-parte do capital, excetuando-se remuneração anual limitada ao valor da taxa referencial do Sistema Especial de Liquidação e de Custódia - Selic para títulos federais.

A sociedade cooperativa deverá também (Princípios Cooperativos):

a) ser constituída pelo número mínimo de associados, conforme previsto no art. $6^{\circ}$ da Lei $\mathrm{n}^{\circ}$ 5.764, de 1971, ressaltando-se que as cooperativas singulares não podem ser constituídas exclusivamente por pessoas jurídicas, nem, tampouco, por pessoa jurídica com fins lucrativos ou com objeto diverso das atividades econômicas da pessoa física;

b) não distribuir qualquer espécie de benefício às quotas-partes do capital ou estabelecer outras vantagens ou privilégios, financeiros ou não, em favor de quaisquer 
Quantidade de residuos sólidos coletados pelo programa Tangará Recicla: uma análise comparativa dos primeiros semestres 2010/2011

Jair de Oliveira

Cleci Grzebieluckas

associados ou terceiros, excetuados os juros até o máximo de doze por cento ao ano atribuídos ao capital integralizado.

c) permitir o livre ingresso a todos os que desejarem utilizar os serviços prestados pela sociedade, exceto aos comerciantes e empresários que operam no mesmo campo econômico da sociedade, cujo ingresso é vedado (Lei no 5.764, de 1971, art. 29 e $\S$ );

d) permitir a cada associado, nas assembleias gerais, o direito a um voto, qualquer que seja o número de suas quotas-partes (Lei nº 5.764, de 1971, art. 42).

A cooperativa de catadores de reciclados é uma sociedade de pessoas cujo objetivo principal é a prestação de serviços. Constitui-se por intermédio da assembléia dos fundadores ou por instrumento público, e seus atos constitutivos devem ser arquivados na Junta Comercial e publicados. Deve ostentar a expressão "cooperativa” em sua denominação, sendo vedado o uso da expressão banco. A cooperativa existe com o intuito de prestar serviços a seus associados, de tal forma que possibilite o exercício de uma atividade comum econômica. (KRUEGER, 2003)

A Lei 9.867/1999 dispõe sobre a criação e o funcionamento de Cooperativas Sociais, constituídas com a finalidade de inserir as pessoas em desvantagem no mercado econômico, por meio do trabalho, fundamentadas no interesse geral da comunidade em promover a pessoa humana e a integração social dos cidadãos. Fazer parte de uma cooperativa facilita e proporciona parcerias com o empresariado possibilitando ganhar dinheiro com o material reciclado. As cooperativas bem organizadas conseguem um bom preço fazendo com que um catador obtenha um ganho médio de 1,5 salário mínimo.

No Brasil em 2008 havia 1.175 cooperativas de catadores de recicláveis com 30.390 cooperados. Em Mato Grosso o número de cooperativas de catadores de reciclados representava apenas 3\% (33 cooperativas) com 289 associados $(0,95 \%$ do total nacional (IBGE, 2008)

Essa parte da nação brasileira é o contribuinte direto que realmente tira da natureza esses materiais sólidos que no futuro seria o indesejável dos ambientes como: rios, matas, e reservas naturais.

\section{PROCEDIMENTOS METODOLÓGICOS}

Esta pesquisa é de natureza exploratória e descritiva com abordagem qualiquantitativa. $\mathrm{O}$ método quantitativo caracteriza-se pelo emprego da quantificação tanto na 
Quantidade de residuos sólidos coletados pelo programa Tangará Recicla: uma análise comparativa dos primeiros semestres 2010/2011

Jair de Oliveira

Cleci Grzebieluckas

modalidade de coleta, quanto no tratamento dos dados por meio de técnicas estatísticas. Já a abordagem qualitativa tem como objetivo entender a natureza de um fenômeno social (RICHARDSON, 1999). Os estudos exploratórios têm como objetivo examinar um tema ou problema de pesquisa pouco estudado, do qual se tem muitas dúvidas, ou não foi abordado antes. E os descritivos consistem em descrever situações, acontecimentos e fatos, isto é, dizer como se manifesta determinado fenômeno (SAMPIERI; COLLADO; LUCIO, 2006).

A pesquisa foi realizada na Cooperativa de Produção de Material Reciclado (COOPERTAN) de Tangará da Serra MT. Para atender a abordagem qualitativa foram entrevistados a Diretora, a Tesoureira, um Conselheiro Fiscal e três cooperados denominados de A, B e C. As entrevistas foram filmadas e posteriormente transcritas. E para a abordagem quantitativa foram feitas visitas in loco e obtidas informações com base nos controles internos da Cooperativa. A coleta de dados aconteceu nos meses de fevereiro e março de 2012. Foram levantadas informações referentes os tipos e quantidades de produtos reciclados nos primeiros semestres de 2010 e 2011. Justifica-se este período em virtude de que a Cooperativa não dispunha de informações dos demais meses dos anos analisados. Após a coleta dos dados foram feitas análises vertical e horizontal. A analise vertical foi utilizada para identificar o produto reciclado de maior representatividade entre os demais. Já por meio da análise horizontal foi comparada a evolução desses produtos.

\section{RESULTADOS E DISCUSSÃO}

\subsection{Histórico da COOPERTAN}

A COOPERTAN iniciou suas atividades na década de 90 quando o material recolhido na cidade era depositado em um terreno na periferia da cidade. Neste local, um grupo de quatro pessoas realizava individualmente a seleção de material reciclado para ser comercializado. Nesse terreno, o grupo trabalhou até 1997, quando então a prefeitura municipal transferiu o depósito do lixo para o novo local chamado Ararão, ou ainda "antigo lixão". A partir de 2004 foi implantado o Aterro Sanitário Municipal localizado na estrada São José, Zona Rural, há aproximadamente 06 quilômetros do centro da cidade, que até então operava sem aprovação dos órgãos ambientais. Após adequações foi aprovado e oficializado passando a operar adequadamente a partir do dia 05 de novembro de 2004 (VIEIRA, 2008). 
Quantidade de residuos sólidos coletados pelo programa Tangará Recicla: uma análise comparativa dos primeiros semestres 2010/2011

Jair de Oliveira

Cleci Grzebieluckas

Como as condições de trabalho dos catadores eram precárias, sem a devida proteção e com material de todas as espécies, a Prefeitura Municipal, através de parceria com o Serviço Autônomo de Água e Esgoto (SAMAE), construiu um barracão com dois banheiros, implantou rede de energia elétrica, perfurou poço artesiano e adquiriu uma prensa. O SAMAE também disponibilizou um caminhão para o transporte do material do aterro até o galpão. Nesse mesmo período foi criado o "Programa Tangará Recicla", com o objetivo de conscientizar a população quanto à separação dos resíduos sólidos domésticos.

Com a criação do programa de reciclagem "Tangará Recicla" a qualidade de parte do material que chegava ao aterro melhorou, diminuindo a necessidade de trabalho direto dos catadores, despertando o interesse por uma melhor estruturação administrativa e por um número maior de catadores surgindo necessidade de uma organização formalizada. Com um quadro de 25 catadores foi criada a Associação dos Catadores de Materiais Recicláveis (COOPERAT), no entanto não foi registrada. Neste mesmo ano houve uma segunda tentativa de organização, e no dia 17 de julho de 2005 foi fundada Associação de Catadores de Material Reciclável (ASCAMARTAS), (VIEIRA, 2008).

Um ano depois, no mês de junho de 2006 foi criada a Cooperativa de Produção de Material Reciclado (COOPERTAN) com 22 associados. No mês de abril de 2008 a cooperativa deixou o barracão do aterro sanitário (Estrada São José) e passou operar na nova sede localizada na Chácara Amazonas, em uma área coberta de $1.305 \mathrm{~m}^{2}$, toda cercada de alvenaria e com infra-estrutura de dois banheiros masculinos e dois femininos, três prensas, dois caminhões e uma esteira. Os dois caminhões fazem a coleta seletiva de segunda a sábado percorrendo todos os bairros da cidade recolhendo os materiais acondicionados em sacos plásticos deixando novas embalagens para serem realizadas novas coletas. A SAMAE também auxilia nesta coleta disponibilizando um caminhão personalizado e com motorista que é auxiliado por três cooperados da Coopertan. Após a coleta o material é armazenado, classificado, prensado e depois comercializado em toda a região, principalmente em Cuiabá.

A COOPERTAN é composta de 29 cooperados. Além da parceria com SAMAE a Coopertan conta com apoio de vários parceiros tais como a Universidade do Estado de Mato Grosso (UNEMAT) por meio do Núcleo de Pesquisa, Extensão e Estudos da Complexidade no Mundo do Trabalho (NECOMT), Núcleo de Participação Social e Economia Solidária (NUPES), Banco do Brasil e Câmara de Vereadores que declarou a Coopertan como entidade de utilidade pública através da Lei 3015 de 13 de Novembro de 2008. 
Quantidade de residuos sólidos coletados pelo programa Tangará Recicla: uma análise comparativa dos primeiros semestres 2010/2011

Jair de Oliveira

Cleci Grzebieluckas

\subsection{Análises dos produtos reciclados}

A tabela 1 apresenta as quantidades, os valores e a participação de cada produto em relação ao total reciclado no primeiro semestre de 2010. Neste ano foram coletadas mais de 159 toneladas de materiais reciclados gerando um montante de $\mathrm{R} \$ 92.558,25$. A linha Politereftalato de etileno (PETs) e o papelão foram os principais produtos que lideraram o ranking representando $38,17 \%$ do total.

Tabela 1 - Quantidades dos produtos reciclados e vendidos pela COOPERTAN no $1^{\circ}$ semestre 2010

\begin{tabular}{|c|c|c|c|c|c|c|c|c|c|c|}
\hline \multirow[b]{2}{*}{ Produtos } & \multicolumn{8}{|c|}{ Quantidades } & \multicolumn{2}{|c|}{ Valores } \\
\hline & jan/10 & fev/10 & $\operatorname{mar} / 10$ & abr/10 & mai/10 & jun/10 & TOTAL & AV \% & $\mathbf{R} \$$ & AV\% \\
\hline Alum. latas & 83 & 560 & 850 & 790 & 127 & 194 & 2604 & 1,63 & 6966,00 & 7,53 \\
\hline Alum.Chaparia & 110 & 85 & 260 & 190 & 140 & 50 & 835 & 0,52 & 1590,00 & 1,72 \\
\hline Alumínio duro & 21 & 90 & 60 & 176 & - & - & 347 & 0,22 & 824,00 & 0,89 \\
\hline Baterias & - & 35 & 11 & 78 & 7.100 & 17.090 & 24314 & 15,25 & 3585,00 & 3,87 \\
\hline Caixaria & & & & 562 & 1.221 & 185 & 1968 & 1,23 & 955,40 & 1,03 \\
\hline Cobre & 51 & - & 348 & 220 & 2.138 & 488 & 3245 & 2,04 & 6888,00 & 7,44 \\
\hline Ferro & 226 & 259 & 70 & 1.567 & 148 & - & 2270 & 1,42 & 432,20 & 0,47 \\
\hline Garrafão vidro & - & 60 & 90 & - & 4.722 & 1.339 & 6211 & 3,90 & 170,00 & 0,18 \\
\hline Inox & & - & 525 & - & 966 & 140 & 1631 & 1,02 & 896,00 & 0,97 \\
\hline Litro & 1.620 & & 119 & 469 & 1.487 & 146 & 3841 & 2,41 & 2268,00 & 2,45 \\
\hline Metal & & 125 & 64 & 965 & - & - & 1154 & 0,72 & 1054,20 & 1,14 \\
\hline Panelas & & & 528 & & - & - & 528 & 0,33 & 844,80 & 0,91 \\
\hline Papelão & 8.080 & 11.996 & 9.090 & 10.300 & - & 135 & 39601 & 24,84 & $9.651,20$ & 10,43 \\
\hline PEAD Branco & 1.500 & 806 & 1.200 & 3.331 & 2.676 & 981 & 10494 & 6,58 & $7.174,80$ & 7,75 \\
\hline PEAD Óleo & & & & 142 & 59 & 40,00 & 241 & 0,15 & 180,00 & 0,19 \\
\hline PEAD Color & & 1.447 & & 5.227 & 800 & 600,00 & 8074 & 5,06 & $4.440,70$ & 4,80 \\
\hline PET & 2.245 & 2.950 & 4.659 & & 600 & 660,00 & 11114 & 6,97 & $13.336,80$ & 14,41 \\
\hline PET Azul & & & & 369 & & & 369 & 0,23 & 442,80 & 0,48 \\
\hline PET Cristal & & & & 7.236 & 3.043 & & 10279 & 6,45 & $12.336,80$ & 13,33 \\
\hline PET Diversas & & 832 & & & & & 832 & 0,52 & 832,00 & 0,90 \\
\hline PET Óleo & & 220 & & & 476 & & 696 & 0,44 & 661,20 & 0,71 \\
\hline PET Verde & 1.103 & & 1.680 & 2.104 & 730 & 760,00 & 6377 & 4,00 & $7.689,60$ & 8,31 \\
\hline Plást. Mole Color & & 90 & & & & & 90 & 0,06 & 54,00 & 0,06 \\
\hline Plástico Mole BR & 4.560 & 1.260 & 252 & 3.860 & 2.300 & $2.250,00$ & 14482 & 9,08 & $5.780,80$ & 6,25 \\
\hline PP Balde/Bacia & & 401 & & & & & 401 & 0,25 & 220,55 & 0,24 \\
\hline PP Colorida & & & & 3.909 & 1.456 & & 5365 & 3,37 & $2.146,00$ & 2,32 \\
\hline PP Cristal & & & & 1.774 & & & 1774 & 1,11 & $1.064,40$ & 1,15 \\
\hline PP Para Choque & 130 & 45 & & 92 & 25 & & 292 & 0,18 & 73,00 & 0,08 \\
\hline TOTAL & & & & & & & 159.429 & 100,00 & $92.558,25$ & 100,00 \\
\hline
\end{tabular}

Fonte: Dados da pesquisa

Volume 1, Número 2

Revista UNEMAT de Contabilidade

Jul./dez. 2012

UNEMAT 
Quantidade de residuos sólidos coletados pelo programa Tangará Recicla: uma análise comparativa dos primeiros semestres 2010/2011

No tocante ao ano de 2011 (Tabela 2) houve uma queda de 7,41\% no total em quantidade e de $22,75 \%$ nos preços dos produtos reciclados em relação ao ano de 2010. Esta redução foi influenciada principalmente pelo papelão que em 2010 este representava 10,43\% e em 2011 foi reduzido para 2,79\%. Destaca-se que houve uma boa evolução no ferro que em 2010 representava $0,47 \%$ e em 2011 atingiu 5,21 ou seja, um aumento de mais de $600 \%$.

Tabela 2 - Quantidades dos produtos reciclados e vendidos pela COOPERTAN no $1^{\circ}$ semestre 2011

\begin{tabular}{|c|c|c|c|c|c|c|c|c|c|c|}
\hline \multirow[b]{2}{*}{ Produtos } & \multicolumn{8}{|c|}{ Quantidades } & \multicolumn{2}{|c|}{ Valores } \\
\hline & jan/11 & fev/11 & mar/11 & abr/11 & mai/11 & jun/11 & TOTAL & AV \% & $\mathbf{R} \$$ & AV\% \\
\hline Alum. latas & 32 & 109 & 141 & 97 & 85 & 88 & 552 & 0,42 & $1.021,00$ & 1,43 \\
\hline Alum.Chaparia & 491 & 103 & 178 & 252 & 28 & 640 & 1.692 & 1,30 & $2.562,00$ & 3,58 \\
\hline Alumínio duro & 98 & - & 125 & - & 29 & & 252 & 0,19 & 402,00 & 0,56 \\
\hline Baterias & 80 & - & - & 80 & - & 100 & 260 & 0,20 & 646,00 & 0,90 \\
\hline Caixaria & 66 & 25 & 12 & - & 60 & & 163 & 0,13 & 211,00 & 0,30 \\
\hline Cobre & 245 & - & 114 & 212 & 40 & 753 & 1.364 & 1,05 & $3.559,60$ & 4,98 \\
\hline Ferro & 7.100 & - & 5.970 & - & 6.052 & 12.620 & 31.742 & 24,42 & $3.722,70$ & 5,21 \\
\hline Garrafão vidro & 125 & - & 145 & 60 & 113 & 45 & 488 & 0,38 & $2.127,00$ & 2,97 \\
\hline Inox & 5 & 18 & 93 & & 45 & 10 & 171 & 0,13 & 321,00 & 0,45 \\
\hline Litro & 325 & - & - & 240 & 80 & 140 & 785 & 0,60 & $1.064,40$ & 1,49 \\
\hline Metal & 45 & - & 66 & 92 & 30 & 184 & 417 & 0,32 & 532,00 & 0,74 \\
\hline Panelas & 48 & - & - & - & 8 & 10 & 66 & 0,05 & 308,00 & 0,43 \\
\hline Papelão & 5.915 & 560 & 480 & - & 4.860 & 6.530 & 18.345 & 14,11 & $1.993,00$ & 2,79 \\
\hline PEAD Branco & 752 & 3.052 & 1.560 & - & 1.356 & 840 & 7.560 & 5,82 & $6.720,60$ & 9,40 \\
\hline PEAD Óleo & 128 & 2.600 & 789 & 653 & 756 & - & 4.926 & 3,79 & $4.926,00$ & 6,89 \\
\hline PEAD Color & - & 1.290 & 302 & - & 2.684 & 465 & 4.741 & 3,65 & $3.701,00$ & 5,18 \\
\hline PET & 1.626 & 1.426 & 192 & 1.532 & 1.117 & 3.412 & 9.305 & 7,16 & $8.699,00$ & 12,17 \\
\hline PET Azul & 1.883 & 1.800 & 663 & & 423 & - & 4.769 & 3,67 & $2.914,56$ & 4,08 \\
\hline PET Cristal & 1.174 & 1.620 & 445 & 1.952 & 2.958 & - & 8.149 & 6,27 & $4.722,22$ & 6,60 \\
\hline PET Diversas & 2.564 & 1.050 & 900 & 245 & 1.985 & 2.495 & 9.239 & 7,11 & $7.545,00$ & 10,55 \\
\hline PET Óleo & 240 & 107 & - & 135 & - & 452 & 934 & 0,72 & 762,60 & 1,07 \\
\hline PET Verde & - & 582 & 631 & 155 & 980 & 2.695 & 5.043 & 3,88 & $5.900,20$ & 8,25 \\
\hline Plást. Mole Color & 780 & 1.296 & - & 1.100 & 456 & - & 3.632 & 2,79 & $1.087,20$ & 1,52 \\
\hline Plástico Mole BR & 814 & 400 & 464 & 425 & 1.030 & 790 & 3.923 & 3,02 & $1.232,77$ & 1,72 \\
\hline PP Balde/Bacia & 1.405 & 185 & 586 & - & 895 & - & 3.071 & 2,36 & $1.228,50$ & 1,72 \\
\hline PP Colorida & - & 1.890 & 3.250 & 890 & 615 & - & 6.645 & 5,11 & $2.657,00$ & 3,72 \\
\hline PP Cristal & 125 & 35 & 33 & & 258 & - & 451 & 0,35 & 450,10 & 0,63 \\
\hline PP Para Choque & - & 550 & - & 125 & 20 & 196 & 891 & 0,69 & 486,00 & 0,68 \\
\hline TOTAL & 26.261 & 18.698 & 17.139 & 8.466 & 26.963 & 32.480 & 130.007 & 100,00 & $71.502,45$ & 100,00 \\
\hline
\end{tabular}

Fonte: Dados da pesquisa

Destaca-se que em determinados períodos há um aumento de determinados produtos, enquanto outros não existem materiais isto se deu em razão de que tendo em vista que a 
Quantidade de residuos sólidos coletados pelo programa Tangará Recicla: uma análise comparativa dos primeiros semestres 2010/2011

Jair de Oliveira

Cleci Grzebieluckas

Cooperativa passava por dificuldade, os cooperados procuravam vender os produtos de maior valor do para atravessadores ganhando com preços inferiores. A Coopertan ainda passa por dificuldades, mas já caminha em busca de mudanças de hábitos, mudança em seu sistema administrativo, no sistema de produção, no sistema de vendas direto às fabricas.

\subsection{RESUMO DAS ENTREVISTAS}

As entrevistas aconteceram nas dependências da cooperativa de forma direcionada conforme segue:

Presidenta:

Jair - Quais as dificuldades encontradas na gestão da Coopertan?

Presidenta - A maior dificuldade encontrada hoje... é na documentação, devido os gestores anteriores deixaram de fazer, agora temos que correr contra o tempo para estar regularizando a situação da cooperativa.

Jair - Além dos problemas mencionados existem outros que afetam o bom desempenho da Coopertan?

Presidenta - O grupo em si "rachou" está repartido, separado, uma desunião mesmo, então a dificuldade grande que a gente encontra. Tem os equipamentos, pagamentos das pessoas, "é batido sempre" na questão dos materiais, questão das vendas, para gente estar conseguindo vender.

Jair - O que é preciso para resolver a situação da Cooperativa?

Presidenta - Um gestor, uma assessoria, porque não sabemos como lidar com isso, então para melhorar nós precisamos ter uma assessoria, por que não temos muito conhecimento... E trabalhar... Ser mais unido para melhorar.

Tesoureira:

Jair - Qual as dificuldades encontradas para gestão na Coopertan?

Tesoureira - Na verdade tudo está difícil, muita dívida pouca receita, só promessas pra nós.

Jair - O que vocês planejam fazer para resolver essa situação?

Tesoureira - Precisamos de muita ajuda, da Unemat, da Samae, de todos os parceiros, só depois vamos ver como vai caminhar essa situação.

Jair - Qual a sua visão em relação à tesouraria da Coopertan? 
Quantidade de residuos sólidos coletados pelo programa Tangará Recicla: uma análise comparativa dos primeiros semestres 2010/2011

Jair de Oliveira

Cleci Grzebieluckas

Tesoureira - Bom pelo que eu sei, vamos tentar controlar mais as contas que a gente faz, quanto às entradas de dinheiro, dizer a todos os cooperados, para não ter problemas.

Cooperado - A

Jair - Qual sua atividade na Coopertan e quais as dificuldades encontradas para desenvolvê-la?

Cooperado A - Trabalho na prensa e a maior dificuldade é que trabalho sozinho e precisaria de alguém para abastecer com o material a ser prensado.

Jair - O que é necessário pra resolver a falta desta mão de obra?

Cooperado A - Para resolver é preciso ter mais pessoas, para puxar "carregar" o material próximo da prensa e ajudar colocar também.

Cooperado B

Jair - Qual a dificuldade encontrada hoje na gestão da Coopertan?

Cooperado B - Falta apoio do Poder Público, principalmente da limpeza do pátio, falta de um veículo próprio, organização, conhecimentos a nível Municipal e Estadual de tudo que diz a respeito de Cooperativa, para conseguir benefícios.

Jair - O que é preciso para resolver a situação da Cooperativa?

Cooperado B - É preciso de mudanças, verbas para investimentos e cursos para os cooperados

Cooperado C

Jair - Qual a dificuldade encontrada na gestão da Coopertan?

Cooperado C - Falta um escritório, organização, falta parceiros, e dinheiro.

Jair - O que é necessário pra resolver essa situação?

Cooperado C - Precisamos de parceiros, investimentos, de um escritório.

\section{CONSIDERAÇÕES FINAIS}

Identificou-se na pesquisa que a quantidade de resíduos sólidos coletados pelo Programa Tangará Recicla, apresentou um declínio relacionado à quantidade e ao preço na comparação entre o primeiro semestre de 2010 e o primeiro semestre de 2011. A coleta seletiva acontece em todos os bairros da cidade, porém, relata-se que, de acordo com as visitas em campo, realizadas na Coopertan. Ao analisar os 29 catadores trabalhando no local, diante da quantidade de materiais recicláveis sólidos acondicionados, observou-se que a 
Quantidade de residuos sólidos coletados pelo programa Tangará Recicla: uma análise comparativa dos primeiros semestres 2010/2011

Jair de Oliveira

Cleci Grzebieluckas

capacidade de produção destes cooperados não são suficientes para separar, classificar, e prensar.

Com relação à insuficiência de mão de obra destaca-se dois itens. O primeiro diz respeito ao problema que a Coopertan enfrenta em obter um local adequado às exigências dos órgãos fiscalizadores para o funcionamento adequado para esta atividade. A segunda evidência esta relacionada com o aumento de resíduos sólidos recicláveis coletado uma vez por semana, observando a possibilidade de coletar pelo menos, duas vezes na semana em cada bairro, após estudos de viabilidade. Pode se pensar que o cidadão tangaraense ainda não está completamente consciente dos impactos ambientais que o lixo pode causar.Verificou-se que há um enfoque maior nas vendas dos produtos mais rentáveis tais como: o alumínio, o cobre, a pet e o plástico, enquanto os demais produtos recicláveis são dispensados.

\section{REFERÊNCIAS}

AGENCIA ESTADO. Produção de lixo cresce 6,8\% no Brasil. Disponível em: $<$ http://www.estadao.com.br/noticias/geral, producao-de-lixo-cresce-68-no-brasil, 710865,0. htm> Acesso em: 16 de março 2012.

BRASIL, Lei $n^{0}$ 5.764, de 16 de dezembro de 1971. Define a Política Nacional de Cooperativismo, institui o regime jurídico das sociedades cooperativas, e dá outras providências. Brasília, D.O.U.,1971.

BRASIL, Lei 9.867, de 10 de novembro de 1999. Dispõe sobre a criação e o funcionamento de Cooperativas Sociais, constituídas com a finalidade de inserir as pessoas em desvantagem no mercado econômico. Brasília, D.O.U.,1999.

BRASIL, Lei $\mathbf{n}^{\mathbf{0}}$ 3015, de 13 de novembro de 2008. Declara de utilidade pública a "Coopertan - cooperativa de produção de material reciclável de tangara da serra".

Caminhos de Geografia, v.1, n.2, p.50-69, 2000. Disponível em:

<http://www.ufpel.edu.br/cic/2009/cd/pdf/CH/CH_00061.pdf>. Acesso em: 20 de Abril 2012.

COELHO, Maria do Rosário Fonseca Folheto. Coleta Seletiva - na escola, na empresa, na comunidade, no município. São Paulo: Secretaria do Meio Ambiente, 2001.

FIGUEIREDO, A. P. Aterro Sanitário Simplificado: uma alternativa para disposição de resíduos sólidos de pequenos municípios. Campina Grande. UFCG, 2005. Dissertação de mestrado.

IBGE- Instituto Brasileiro de Geografia e Estatística. Indicadores sociais municipais 2000. Disponível em:

<http://www.ibge.gov.br/home/estatistica/populacao/indicadores_sociais_municipais/ tabela1a.shtm>. Acesso em: 16 de Abril de 2012. 
Quantidade de residuos sólidos coletados pelo programa Tangará Recicla: uma análise comparativa dos primeiros semestres 2010/2011

Jair de Oliveira

Cleci Grzebieluckas

IBGE- Instituto Brasileiro de Geografia e Estatística. Pesquisa Nacional de Saneamento

Básico de 2008. Disponível em:

<http://www.sidra.ibge.gov.br/bda/pesquisas/pnsb/default.asp?o=24\&i=P.>. Acesso em $16 \mathrm{de}$ março de 2012.

IBGE- Instituto Brasileiro de Geografia e Estatística. Indicadores sociais municipais 2010.

Disponível em:

<http://www.ibge.gov.br/home/estatistica/populacao/indicadores_sociais_municipais/tabela1a .shtm>. Acesso em: 16 de março de 2012.

IBGE-Instituto Brasileiro de Geografia e Estatística. Disponível em:

<http://www.ibge.gov.br/ibgeteen/datas/gari/cuidando.html> Acesso em: 14 jun. 2012>.

KRUEGER, Guilherme Advogado da OCB recomenda cautela de contratação na cooperativa. Associação Nacional de Cooperativas de Trabalho: disponível em; http://www.antc.com.br acesso em: 16 de Abril 2012.

LEFF, E. Saber Ambiental. Sustentabilidade, racionalidade, complexidade, poder. Petrópolis: Vozes, 2001.

LEITE, Paulo Roberto. Logística reversa: meio ambiente e competitividade. São Paulo Prentice Hall, 2003.

LIMA, J. D. Gestão de Resíduos Sólidos Urbanos no Brasil.. Rio de Janeiro: ABES, 2001.

PIERONI apud Campos; A coleta seletiva de resíduos sólidos, 1994.

RIBEIRO, T. F.; LIMA, S. do C. Coleta seletiva de lixo domiciliar - estudo de casos.

RICHARDSON, Robert Jarry. Pesquisa social: métodos e técnicas. São Paulo: Atlas, 1999.

SAMPIERI, Roberto H.; COLLADO, Carlos F.; LUCIO, Pilar B. Metodologia de Pesquisa. 3. Ed, São Paulo: McGraw Hill, 2006.

VIEIRA, Maila Karling. Contabilidade de cooperativas: um estudo de caso a cerca da contabilidade da COOPERTAN. 2008. f 146 (Trabalho de Conclusão de Curso- Ciências Contábeis) Universidade do Estado de Mato Grosso - UNEMAT.

WALDMAN, Maurício; SCHNEIDER, Dan Moche Guia ecológico doméstico. São Paulo: Contexto, 2000. 